\title{
O polimento da imagem pública de Luiz Inácio Lula da Silva passando pelos conceitos de hegemonia, política de opinião e simulacro ${ }^{1}$
}

\author{
Álvaro Nunes Larangeira ${ }^{2}$ \\ Universidade Tuiuti do Paraná \\ larangeira@terra.com
}

\begin{abstract}
Resumo: O objetivo deste artigo é acompanhar o polimento do discurso e da imagem de Luiz Inácio Lula da Silva de 1980, ano da fundação oficial do Partido dos Trabalhadores, a 2006, quando foi reeleito à presidência da República, valendo-se das reflexões a respeito dos conceitos de hegemonia, política de opinião e simulacro. Em decorrência destas aplicações, divide-se o período em três fases: na primeira (1980/2002) impunha-se como meta o partido tornar-se hegemônico na sociedade civil; na segunda, de 2002 a 2005, imperou a preocupação de adequar Lula à diversidade de públicos $e$ opiniões; e na terceira, em razão das denúncias de mensalão e afins, o recurso do simulacro, tendo como referências Getúlio Vargas e o próprio Luiz Inácio Lula da Silva.
\end{abstract}

Palabras -chave: comunicação; política; discurso; imagem.

Abstract: The objective of this paper is to analyse the "lapidation" (polishment) of the image and the discours of Luis Inacio Lula da Silva from 1980 (the official foundation of Workers Party) to 2006 when he was reelected as the president of the country. Our basis of reflection will be the concepts of hegemony, politics of opinion and simulacra. Due to this application we've divided the period in three phases: the first (1980/200o) the goal of the Worker's Party was to become hegemonic in the brazilian civil society; on the second phase, from 2002 to 2005, the main concern was to fit Lula's discours to the diversity of public and opinions; and, on the third phase, due to corruptions scandals, simulacra was established connecting the image of Lula to the references of the former President Getúlio Vargas and the first image of Lula himself.

Key words: communication; politics; discours; image.

\footnotetext{
1 Trabalho apresentado no GT Imagem Pública Política do I Congresso Anual da Associação Brasileira de Pesquisadores de Comunicação e Política, ocorrido na Universidade Federal da Bahia - Salvador - 2006

2 Doutor em Comunicação Social pela PUCRS e professor do Mestrado em Comunicação e Linguagens da Universidade Tuiuti do Paraná. Autor de Comunicação Monoteísta - a fonte dos discursos do Partido dos Trabalhadores e da Rede Brasil Sul (Sulina, 2006).
} 


\section{Introdução}

No início, em 1989, Lula Lá. Agora, em 2006, para a reeleição, Lula de novo com a força do povo. Sem esquecer do Lulinha Paz e Amor, de 2002. Os slogans às campanhas presidenciais de Luiz Inácio Lula da Silva são sintomáticos dos ritos de passagem galgados não só pela pessoa do candidato como também pelo Partido dos Trabalhadores agremiação política que representa há 26 anos -, e simbolizam o ideário pelo qual tanto o personagem quanto o partido são orientados. Estes bordões representam principalmente, de acordo com a proposição deste trabalho, o processo de polimento da imagem pública de Luiz Inácio Lula da Silva.

O primeiro, Lula Lá, compreende o período de 1980 a 2001. Nessas duas décadas Lula disputou as eleições presidenciais de 1989, 1994 e 1998, sendo derrotado por Fernando Collor de Mello na primeira e por Fernando Henrique Cardoso nas duas últimas. Nessa época, impregnava o imaginário petista a busca pela conquista do segmento da sociedade brasileira denominado pelos teóricos e militantes petistas como as classes exploradas. Assim consta no Manifesto do Partido dos Trabalhadores, apresentado em 10 de fevereiro de 1980, dia da fundação oficial do PT: "Nascendo das lutas sociais... o partido surge para defender os interesses dos operários industriais, assalariados do comércio e dos serviços, funcionários públicos, moradores da periferia, trabalhadores autônomos, camponeses, trabalhadores rurais, mulheres, negros, estudantes, índios e outros setores explorados" (GADOTTI, 1989, p. 52). Em suma, quase toda a população brasileira.

Impunha-se como meta cooptar a maioria da sociedade civil, idéia própria do conceito de hegemonia de Antonio Gramsci. Para tanto seria fundamental basear-se no pensador italiano e conquistar a mente, e não apenas o corpo, deste expressivo segmento social, compreendendo o termo hegemonia "no sentido de hegemonia política e cultural de um grupo social sobre toda a sociedade, como conteúdo ético do Estado." (in BOBBIO, 2002, p. 56). Entretanto, em razão das malfadadas tentativas à presidência, entendeu o partido que apenas com as classes trabalhadoras não chegaria ao Palácio do Planalto. Precisaria estender a mão àqueles antes considerados exploradores. Afinal, nem tudo se resumia a dicotomias. Daí a importância de enxergar o rico emaranhado de públicos na 
intrincada opinião pública brasileira. Nesse ponto, inclui-se a relevância do conceito de política de opinião, assim definido por Wilson Gomes: "Chama-se de política de opinião os empreendimentos que se dedicam às funções fundamentais da chamada 'conquista da opinião pública': a) a construção da opinião; b) o ajuste entre a opinião que o público deseja e a opinião publicada; c) a manutenção, ou seja, o empreendimento que visa manter como opinião do público a opinião particular” (In HOHLFELDT, 2001, p. 79). Em conseqüência do novo paradigma, o PT aliou-se ao Partido Liberal, oferecendo a vaga de vice-presidente na eleição de 2002, e contratou o publicitário Duda Mendonça, enfrentando o descontentamento de muitos militantes que o execravam pela coordenação de campanhas de políticos como Paulo Maluf, por exemplo. O resultado foi a alteração da imagem do candidato Lula, passando de "radical" a diplomático e negociador - Lula Paz e Amor -, e a vitória na eleição presidencial, graças também aos fundamentais votos liberais em São Paulo e Minas Gerais, onde o PL tinha a sua base e em cujos colégios eleitorais, os maiores do país, Lula havia perdido nas três eleições anteriores.

Na metade de 2005 a irrupção das acusações da compra dos votos de deputados e senadores para apoiar o governo Lula, dos depósitos em contas de oito deputados petistas de dinheiro oriundo do publicitário Marcos Valério, envolvido em negociatas escusas, dos comprovantes de depósitos bancários nas contas do diretor-geral e do tesoureiro do PT feitos pelo mesmo Marcos Valério, da violação do sigilo bancário dum caseiro que acusava o ministro da economia Antonio Palocci de reunir-se com lobistas ex-assessores seus, além da admissão do pagamento de Duda Mendonça com dinheiro proveniente do caixa dois, desestabilizou o discurso ético petista e impôs novas providências para assegurar a imagem do presidente Lula. O mesmo passou a colocar-se como vítima da traição de excompanheiros do partido e da gana dos inimigos descontentes com o seu programa de governo popular. Para tanto, Lula recorreu a analogias com Getúlio Vargas, assumindo um simulacro, na acepção do sociólogo francês Jean Baudrillard, do ex-presidente populista, conhecido como o "Pai dos Pobres". Não por menos a campanha de Luiz Inácio Lula da Silva adotou como slogan Lula de novo com a força do povo, numa clara alusão a Getúlio Vargas. Portanto, com base nas reflexões de Antonio Gramsci - conceito de hegemonia -, 
Wilson Gomes - conceito de política de opinião - e Jean Baudrillard - conceito de simulacro -, pretende-se mostrar a forma como foi polida a imagem pública de Lula.

\section{Em busca da hegemonia pura}

Iniciemos pela acepção gramsciana de partido. Para ele, são três os fatores fundamentais para a existência da agremiação política: "1) Um elemento difuso, de homens comuns, médios, cuja participação é oferecida pela disciplina e pela fidelidade... 2) O elemento de coesão principal, que centraliza no campo nacional, que torna eficiente e poderoso um conjunto de forças que, abandonadas entre si mesmas, representariam zero ou pouco mais... 3) Um elemento médio, que articule o primeiro com o segundo elemento, colocando-os em contato não só 'físico', mas moral e intelectual”' (1968, p. 26). A confluência destes três pontos percebe-se na gênese do Partido dos Trabalhadores.

A cobrança interna por disciplina e fidelidade partidárias é característica marcante do partido. Em 1985, ao contrariarem a decisão do boicote à eleição indireta para presidente da República no Colégio Eleitoral, os deputados federais Airton Soares, Bete Mendes e José Eudes foram expulsos do partido. Na década de 1990, foi a vez de algumas tendências serem alijadas sob a justificativa de tornarem-se partidos dentro do partido. Militantes saíram e formaram em seguida o Partido da Causa Operária (PCO) e o Partido Socialista dos Trabalhadores Unificados (PSTU). Em 2003, a senadora Heloisa Helena e os deputados federais João Fontes, José "Babá" Batista e Luciana Genro acabaram desligados pelo diretório nacional do PT em razão da votação contra projetos do governo Lula.

A formação política diversificada exemplifica a segunda característica listada por Gramsci. O PT reuniu representantes do sindicalismo brasileiro formado nas greves contra o regime pós-64, integrantes do clero progressista alinhados com a Teologia da Libertação e as Comunidades Eclesiais de Base, trabalhadores rurais das Ligas Camponeses, da Comissão Pastoral da Terra e do Movimento dos Trabalhadores Rurais Sem Terra (MST), correntes e organizações marxistas mantidas na clandestinidade durante a ditadura militar, além dos intelectuais, universitários, funcionários públicos e profissionais liberais identificados com o pensamento socialista e a redemocratização imediata do país. O PT tornou-se pólo agregativo e irradiador em âmbito nacional. Do contrário, que peso teriam 
no cenário político brasileiro nomes como Democracia Socialista, Articulação de Esquerda, Ação Popular Socialista, Movimento PT e o tão citado desde o ano passado Campo Majoritário? Nenhum, se não constituíssem os principais movimentos/tendências/correntes do PT.

Em relação ao terceiro ponto, de compreender não apenas o físico mas também o moral e o intelectual, Gramsci vale-se dos conceitos de direção política e direção cultural. O primeiro representaria a formação de uma "vontade coletiva", no caso decorrente da correlação e junção de forças em prol de objetivos semelhantes - como criar um partido de esquerda peculiar no histórico político brasileiro - , e o segundo seria o canal para a reformulação intelectual e moral da sociedade. Desta maneira, o conceito de hegemonia de Gramsci superaria o de Lenin, para quem o mais importante seria a direção política. Norberto Bobbio explica a diferença:

"Poder-se-ia dizer que em Lenin prepondera o significado de direção política; em Gramsci, o de direção cultural. Mas é preciso acrescentar que essa diversa predominância assume dois aspectos diversos: a) para Gramsci, o movimento da força é instrumental e, portanto, subordinado ao momento da hegemonia, ao passo que em Lênin, nos escritos da revolução, ditadura e hegemonia procedem de pari passu, e, de qualquer modo, o momento da força é primário e decisivo; b) para Gramsci, a conquista da hegemonia precede a conquista do poder, ao passo que em Lênin a acompanha e mesmo a ela se segue". (BOBBIO, 2002, p. 68).

Assim, em Gramsci, a hegemonia não se restringe apenas ao campo político, ao estatuto e conquista do Estado, à criação de um novo partido, e sim a proposição duma nova concepção de mundo (BOBBIO, 2002, p. 69). Neste ponto, é importante conhecer a conceituação de Gramsci a respeito de sociedade civil e a sua definição de catarsis neste processo envolvendo estrutura/superestrutura. O pensador italiano distingue dois planos superestruturais: "O que pode ser chamado de 'sociedade civil' (isto é, o conjunto de organismos chamados comumente de 'privados') e o da 'sociedade política ou Estado', que correspondem à função de 'hegemonia' que o grupo dominante exerce em toda a sociedade e àquela de 'domínio direto' ou de comando, que se expressa no Estado e no governo 'jurídico' (GRAMSCI, 1985, pp. 10-11). Se em Marx a sociedade civil representaria o conjunto abarcando as relações industriais, comerciais, materiais, para Gramsci compreenderia imaginários ideológicos e culturais (BOBBIO, 2002, p. 55). A hegemonia 
sob a diretriz da sociedade civil cria uma nova ideologia e conseqüentemente a alteração da consciência. Daí a relevância do processo catártico, explicado por Gramsci: "Pode-se empregar a expressão 'catarsis' para indicar a passagem do momento puramente econômico (ou egoísta-passional) ao momento ético-político, isto é, a elaboração superior da estrutura em superestrutura na consciência dos homens. Isto significa, também, a passagem do 'objetivo ao subjetivo' e da 'necessidade à liberdade”' (1981, p. 53). O estudioso da obra gramsciana Carlos Nelson Coutinho ressalta a dimensão política do conceito de catarse:

"O momento 'catártico' é aquele em que o homem afirma sua liberdade em face das estruturas sociais, revelando que - embora condicionado pelas estruturas e, em particular, pelas estruturas econômicas - é capaz, ao mesmo tempo, de utilizar o conhecimento dessas estruturas como fundamento para uma práxis autônoma, para a criação de novas estruturas, ou, como ele [Gramsci] diz, para “gerar novas iniciativas”' (COUTINHO, 1996, p. 106).

É imbuído deste pressuposto catártico que o Partido dos Trabalhadores se forja, conforme o artigo $\mathrm{n}^{\circ} 1$ do seu estatuto: "O Partido dos Trabalhadores é uma associação voluntária de cidadãs e cidadãos que se propõem a lutar por democracia, pluralidade, solidariedade, transformações políticas, sociais, institucionais, econômicas, jurídicas e culturais, destinadas a eliminar a exploração, a dominação, a opressão, a desigualdade, a injustiça e a miséria, com o objetivo de construir o socialismo democrático" (2004, p. 17). $\mathrm{Na}$ apresentação da nova edição do estatuto comemorativa dos 25 anos, o então presidente do PT, José Genoino, reafirma o propósito de "mudar a tradição e história dos partidos políticos brasileiros. Essa tradição histórica se explicita pela existência de partidos gelatinosos, invertebrados, fracos e pouco representativos do eleitorado brasileiro. O ideal de partido que professamos nega essa tradição" (p. 11). A estratégia da representatividade se materializa na figura de Luiz Inácio Lula da Silva, presidente do Sindicato dos Metalúrgicos de São Bernardo do Campo e Diadema e ícone do movimento sindicalista do ABC paulista do final da década de 1970, o maior do país e base da contestação ao regime militar de 1964 com as greves de 1979 e 1980. A figura do operário é consonante com os lemas do partido nas primeiras eleições, Trabalho, Terra e Liberdade e Trabalhador vota em trabalhador. O Partido dos Trabalhadores alinha-se às organizações sindicais e rurais, aos movimentos sociais populares e estudantis, diferenciando-se dos partidos representativos 
da classe média conservadora e do empresariado, como consta em sua Carta de Princípios, de $1^{\circ}$ de maio de 1979: "Repudiando toda forma de manipulação política das massas exploradas, incluindo sobretudo as manifestações próprias do regime pré-64, o PT recusase a aceitar em seu interior representantes das classes exploradoras. Vale dizer, o Partido dos Trabalhadores é um partido sem patrões" (GADOTTI; PEREIRA, 1989, p. 38).

\section{Do Lula quase Lá ao Lula Paz e Amor do Palácio do Planalto}

O ideário de ser o porta-voz da sociedade civil decantada perdurou por duas décadas e elevou o Partido dos Trabalhadores à ponta do cenário político brasileiro, timoneado por Luiz Inácio Lula da Silva. Neste período, Lula ocupou a presidência do PT de 1980 e 1994 e figurou como presidente de honra de 1994 a 2002, quando finalmente venceu a eleição ao Palácio do Planalto. Seu primeiro teste eleitoral foi como candidato a governador de São Paulo em 1982. Ficou em quarto lugar com 10\% dos votos. Quatro anos depois se elegeu deputado constituinte com 650 mil votos. Em 1989, definido pelo partido para concorrer à presidência, consegue chegar ao segundo turno superando o trabalhista Leonel Brizola por uma diferença de um ponto percentual, mas perde o confronto com Fernando Collor de Mello por menos de 5\% (42,7 a 37,8\%). A disputa tem situações peculiares. Brizola, a muito custo, apóia Lula no segundo turno embora sempre dizendo que Lula, por causa da sua imagem de radical, é o adversário escolhido pelo grande empresariado e pelas forças de direita. Polarizada a disputa, Collor aproveita esse ponto para incutir medo no eleitorado, associando o candidato petista ao fim do direito à propriedade privada, confisco dos bens, invasões de terra, ocupação de fábricas, etc.

Collor de Mello é afastado do poder em 1992, assume Itamar Franco e nas primeiras sondagens para a eleição de 1994 Lula desponta na frente. O favoritismo sustenta-se até julho de 1994, quando entra em circulação a moeda Real, segundo estágio do plano de estabilização da economia aplicado na gestão de Fernando Henrique Cardoso como ministro da Fazenda. O sucesso das medidas de contenção inflacionária, sem a necessidade de congelamento de salários e preços (Sarney) e nem confisco da poupança (Collor), e o ataque petista ao plano econômico sucumbiram a vantagem de Lula e Fernando Henrique venceu ainda no primeiro turno. Na disputa seguinte, sustentado pelo 
êxito do Real, pelas medidas corretivas do plano econômico, pela aprovação da emenda à reeleição por meio da distribuição de propinas e pela benevolente ausência de críticas por parte dos principais meios de comunicação, FHC reelegeu-se também em primeiro turno.

Atordoados pela terceira derrota e assombrados pelo espectro de um possível quatro insucesso, Lula e o seu grupo de sustentação dentro do partido, o qual era o majoritário, decidiram rever as políticas puristas na escolha de alianças e dar o braço a torcer ao potencial do marketing político. Enfim, resolveram abrir a guarda em acordos com partidos antes criticados e planejar uma política de opinião e não mais sonhar com a aquiescência da tão sonhada sociedade civil politizada. Para o primeiro caso, aliou-se ao Partido Liberal e, com isso, em 2002, conseguiu pela primeira vencer seus adversários, tanto no primeiro como no segundo turno, em São Paulo e principalmente em Minas Gerais. Para resolver o segundo ponto, recorreu a Duda Mendonça, expert em marketing político. Ricardo Kotscho, assessor de comunicação de Lula por três vezes, revela a estratégia para a eleição de 2002:

"Ao analisar as pesquisas a favor e contra, Duda Mendonça sintetizou qual seria nosso trabalho: 'Nós temos um terço do eleitorado com Lula, um terço contra Lula e um terço que não é a favor nem contra. É por esse eleitor que nós precisamos brigar, ao mesmo tempo em que trabalharemos para diminuir o índice de rejeição" (2006, p. 220).

O lema Trabalhador vota em trabalhador cedeu lugar ao $A$ esperanca vencen o medo. A imagem do "sapo barbudo", como uma vez Brizola referiu-se a Lula, foi substituída pela do Lula conciliador, sereno, sensato e apaziguador: o Lula Paz e Amor. Tudo isso em decorrência dos estudos da política de opinião e das táticas em pautar e direcionar o enfoque dos meios de comunicação. Duda Mendonça desempenhou com competência as atribuições esperadas de um profissional da área, como bem explica Wilson Gomes: "O melhor agente nesse campo realiza o duplo serviço de produzir uma campanha que 'venda' a 'marca' ou imagem ao público e, ao mesmo tempo, transforme-se, ela mesma, em fato político irresistível para o sistema informativo" (2004, p. 157). Ao lembrarmos da avaliação de Duda Mendonça do cenário inicial de 2002, um terço identificava-se com Lula de maneira inconteste - a sociedade civil gramsciana? Em relação ao outro um terço, seria preciso conquistar suas opiniões, ou melhor ainda, formá-la. 
"Criar uma imagem... não é certamente construir ele mesmo uma imagem, mas organizar os materiais de tal arte que o público a produza: construir é fazer construir. $O$ criador de imagens na verdade produz apenas discursos e expressões caracterizadoras, que pode realizar na recepção as concepções caracterizadoras que constituem a imagem" (GOMES, 2004, p. 268)

A política de opinião formula-se no processo de conversão da opinião particular em opinião do público, e na opinião dos públicos como uma opinião pública. Portanto, perpassa pelos campos dos meios de informação, do universo dos formadores de opinião e da circulação e consumo de opiniões pelos segmentos, estratos e componentes constituintes do que seria a opinião pública. Alimentá-los de compreensões a partir da compreensão dos gostos destes públicos. À imagem de radicalismo, o contraponto das feições serenas, atitudes reflexivas, posturas pensadas, acordos políticos trabalhados, conversações com adversários, visitas a entidades empresariais, participação de fóruns como o de Davos. À crítica de proselitismo, o estreitamento do contato face a face, o comprometimento com políticas públicas, a interlocução constante com os movimentos sociais, a lembrança da trajetória política. E a associação da política de opinião com a política de imagem:

"Movimento aparentemente inverso àquele da arte política que se crê normal, a política de imagem não procura propriamente que o público deseje ou considere valorosos a posição que se sustenta e/ou o ator que se apresenta, mas busca identificar o que o público já deseja e já considera valoroso para acomodar a isso a posição do ator" [grifo do autor] (GOMES, 2004, p. 277)

\section{Da política de opinião ao simulacro}

Ao participar do primeiro encontro do Diretório Nacional depois do êxito da reeleição, Lula convoca a militância do partido a reconstruir a imagem de referência ética na política brasileira. Tem ele motivos para tanto. A militância petista sempre exaltou o peculiar comportamento no trato do bem público, no exercício legislativo, na integridade partidária. Daí a crítica a "partidos gelatinosos, invertebrados, fracos" mencionados por Genoino. Partidos esses afeitos à corrupção nas esferas legislativa e executiva, a negociatas escusas, a alianças oportunistas. O discurso ético do PT perdurou praticamente imaculado de 1980 até a metade do ano passado. Em junho de 2005, o deputado federal Roberto Jefferson, presidente do Partido Trabalhista Brasileiro (PTB) e acusado de comandar 
esquema de recebimento de propina nos Correios, depõe na CPI dos Correios e denuncia integrantes da cúpula do PT pela compra de votos de deputados e senadores para apoiar o governo Lula. A fonte dos recursos seria o publicitário Marcos Valério Fernandes. Jefferson citou o secretário-geral do PT, Silvio Ferreira, o tesoureiro Delúbio Soares e o ministro da Casa Civil, José Dirceu, a quem se referia como "o chefe da máfia”. Mesmo negando envolvimento no que foi denominado de Mensalão, José Dirceu renunciou ao cargo. A descoberta de comprovantes bancários das transações entre o publicitário e o PT resultou nos afastamentos de Silvio Ferreira e Delúbio Soares, além de pedidos do Conselho de Ética do Congresso pela cassação de deputados petistas agraciados com depósitos de Marcos Valério. Genoino também renunciou à presidência do PT, mas por outro motivo: um assessor de seu irmão deputado estadual petista alagoano foi detido em São Paulo com US\$ 85 mil na mala e US\$ 100 mil escondidos no corpo.

Na bem-sucedida campanha à reeleição, Lula faz uso das solenidades oficiais e dos comícios para se queixar da perseguição por parte da imprensa e "duma elite aristocrática que manda neste país desde que Cabral chegou aqui”, diz-se traído pelos integrantes do Partido dos Trabalhadores - pelo qual se elegeu à presidência - envolvidos em acusações da compra de dossiê contra adversários e do aliciamento financeiro de parlamentares para aumentar a base governista no Congresso Nacional, tachando-os de aloprados e traidores, recorre a alusões com Tiradentes, Jesus Cristo e Judas Iscariotes e compara-se a Juscelino Kubitschek e principalmente Getúlio Vargas. Juscelino, pelo emaranhado de acusações e pedidos de Comissões Parlamentares de Inquérito durante o seu governo. E Getúlio Vargas, pelo descontentamento "da elite aristocrática que manda neste país desde que Cabral chegou aqui" com as políticas sociais do governo petista. Em diversas situações, Lula repete gestos do líder populista gaúcho, que governou o Brasil em dois períodos - de 1930 a 1945 e de 1951 a 1954 -, assemelhando-se a um simulacro de Getúlio, não no sentido de engodo, fingimento, mas de parecença, semelhança. Marilena Chaui discorre sobre a etimologia e as interpretações do termo:

Simulacrum é uma palavra latina que vem de similis, que significa o semelhante. De similis vêm as palavras simul, fazer junto, mas também competir, rivalizar, e similitudo, semelhante, analogia, comparação. De similis vem o verbo simulare, que significa representar exatamente, copiar, tomar a aparência de; este último 
significado leva o verbo a significar também fingir, simular. Ou seja, simulacrum tanto pode significar uma representação ou cópia exata como um fingimento, uma simulação" (2006, p. 82).

A, no mínimo, duplicidade de sentido na perspectiva etimológica apontada por Chaui converge com a conceituação feita por Jean Baudrillard. O sociólogo francês lista três categorias de simulacro:

“- os simulacros naturais, naturalistas, baseados na imagem, na imitação e no fingimento, harmoniosos, optimistas e que visam a restituição ou a instituição ideal de uma natureza à imagem de Deus;

- simulacros produtivos, produtivistas, baseados na força, na sua materialização pela máquina e em todo o sistema de produção...;

- simulacros de simulação, baseados na informação, no modelo, no jogo cibernético (1981, p. 151)

O primeiro, argumenta Baudrillard, corresponderia ao imaginário da utopia; o segundo, ao da ficção científica, e o terceiro, da hiper-realidade. No tocante ao objeto deste trabalho poder-se-ia fundir as três categorias e aplicá-las a Lula, porque ao valer-se das atitudes e estratégias arroladas ele tenta "reconstituir in vitro, até aos mínimos detalhes, as peripécias de um mundo anterior, os acontecimentos, as personagens, as ideologias acabadas, esvaziadas de sentido, do seu processo original, mas alucinantes de verdade retrospectiva" (BAUDRILLARD, 1981, p. 153). Essa composição argumentativa para juntar as categorias de Baudrillard com a imagem de Luiz Inácio Lula da Silva foi um procedimento de simulacrum pois "nada distingue esta operação da gestão e da própria operação do real: já não há ficção" (1981, ibidem). Essa ressurreição de períodos históricos é tão perfeita que passa a ser o espelho ou o próprio acontecimento, como o procedimento psicossomático (BAUDRILLARD, 2001, p. 10) ou o inebriamento argumentativo perceptível nos debates da disputa presidencial ou nos comícios, nos quais Lula engolfavase em dados e números de tal maneira que se dizia a única referência a se cotejar, tornandose o simulacro de si mesmo. 


\section{Consideração final}

O propósito deste artigo foi mostrar o polimento pelo qual passou a imagem pública do presidente Luiz Inácio Lula da Silva do período de 1980, ano da fundação do Partido dos Trabalhadores, até 2006, ano em que foi reeleito. Para fundamentar esse processo recorreu-se aos conceitos de hegemonia, política de opinião e simulacro, desenvolvidos respectivamente pelo italiano Antonio Gramsci, pelo brasileiro Wilson Gomes e pelo francês Jean Baudrillard. A ilustração da proposição deste trabalho foi obtida pela análise dos documentos oficiais do Partido dos Trabalhadores e pelos discursos do candidato e presidente Lula nos períodos correspondentes às fases apontadas conforme o imaginário petista que permeava cada um dos momentos mencionados.

\section{Referências:}

ATTUCH, Leonardo. A CPI que abalou o Brasil. São Paulo: Futura, 2005.

BAUDRILLARD, Jean. A ilusão vital. Rio de Janeiro: Civilização Brasileira, 2001. . Simulacros e simulação. Lisboa: Relógio d'Água, 1991. . Tela total. Porto Alegre: Sulina, 1997.

BOBBIO, Norberto. Ensaios sobre Gramsci e o conceito de sociedade civil. $2^{\mathrm{a}}$ ed. São Paulo: Paz e Terra, 2002.

BOBBIO, N.; MATTEUCCI, N; PASQUINO, G. Dicionário de política. Brasília: UnB, vols. 1 e 2, 1994.

CHARAUDEAU, Patrick. Discurso político. São Paulo: Contexto, 2006.

CHAUI, Marilena. Simulacro e poder - uma análise da mídia. São Paulo: Perseu Abramo, 2006.

COUTINHO, Carlos Nelson. Marxismo e política - a dualidade de poderes e outros ensaios. $2^{\text {a }}$ ed. São Paulo: Cortez Editora, 1996.

GADOTTI, Moacir; PEREIRA, Otaviano. Pra que PT - origem, projeto e consolidação do Partido dos Trabalhadores. São Paulo: Cortez Editora, 1989. 
GOMES, Wilson. Transformações da política na era da comunicação de massa. São Paulo: Paulus, 2004.

. Opinião pública política hoje - uma investigação preliminar. In:

HOHLFELDT, Antonio (org.). Práticas mediáticas e espaço público. Porto Alegre: Pucrs, 2001.

GRAMSCI, Antonio. Concepção dialética da história. $4^{\text {a }}$ ed. Rio de Janeiro: Civilização Brasileira, 1981.

. Os intelectuais e a organização da cultura. $5^{\mathrm{a}}$ ed. Rio de Janeiro: Civilização Brasileira, 1985.

Maquiavel, a política e o Estado moderno. Rio de Janeiro: Civilização Brasileira, 1968.

GRUPPI, Luciano. O conceito de hegemonia em Gramsci. Rio de Janeiro: Graal, 1980.

KOTSCHO, Ricardo. Do golpe ao Planalto - uma vida de repórter. São Paulo: Companhia das Letras, 2006.

MAINGUENEAU, Dominique. Análise de textos de comunicação. São Paulo: Cortez Editora, 2000.

Gênese dos discursos. Curitiba: Criar Edições, 2005.

MOREL, Mario. Lula - o início. Rio de Janeiro: Nova Fronteira, 2006.

NOSSA, Leonencio; SCOLESE, Eduardo. Viagens com o presidente. Rio de Janeiro: Record, 2006.

PARTIDO DOS TRABALHADORES. Estatuto. São Paulo: Perseu Abramo, 2004.

RODRIGUES, Fernando. Políticos do Brasil. São Paulo: Publifolha, 2006

SILVA, Juremir Machado da Silva. O governo Lula em revista: o jornalismo como fenômeno de descobrimento (a cobertura da Veja). In: REVISTA FAMECOS, no 29, abr. 2006.

SKIDMORE, Thomas. Uma história do Brasil. São Paulo: Paz e Terra, 1998. 